\title{
EDIBLE WILD MUSHROOMS OF ETHIOPIA: NEGLECTED NON-TIMBER FOREST PRODUCTS
}

\section{SETAS SILVESTRES COMESTIBLES DE ETIOPÍA: PRODUCTOS FORESTALES NO MADEREROS MENOSPRECIADOS}

\author{
Tatek Dejene ${ }^{1,2}$, Juan Andrés Oria-de-Rueda' and Pablo Martín-Pinto ${ }^{1}$ *
}

\begin{abstract}
'Fire and Applied Mycology Laboratory, Sustainable Forest Management Research Institute, University of Valladolid (Palencia). Avda. Madrid 44 34071. Palencia, Spain. ${ }^{2}$ Central Ethiopia Environment and Forestry Research Center. P.O. Box 30708, Addis Ababa, Ethiopia.

*Corresponding author (pmpinto@pvs.uva.es)
\end{abstract}

\section{SUMMARY}

This review summarizes existing ethnomycological work in Ethiopia. Although the literature to which we had access were scanty and limited in their scope, comprehensive issues such as the culture of collection and use of edible wild mushrooms in the country are summarized. In this review, moreover, a check list of available wild edible and medicinal mushrooms and their niches are also documented. The review reveals that wild mushrooms are the most neglected non-timber forest products (NTFPs). They are poorly studied and undocumented in Ethiopia as compared to other NTFPs and their importance for the livelihood of the local communities is also overlooked. Recognition of this resource is also hampered by the lack of taxonomic studies; most of the species are simply known locally by the shared common name "Enguday". Thus, this document can serve as baseline information and indicator for further studies to facilitate the wider use, promotion and conservation of wild mushrooms in Ethiopia.

Index words: Wild mushrooms, Enguday, ethnomycology, Nontimber forest products, Ethiopia.

\section{RESUMEN}

Este artículo resume los trabajos previos existentes sobre Etnomicología en Etiopía. Aunque los documentos a los que se ha tenido acceso son escasos y limitados en cuanto a sus objetivos, se presenta una valiosa y extraordinaria información sobre la recolección y consumo de hongos silvestres comestibles en el país. Además, se presenta un listado de los hongos utilizados por su valor comestible y medicinal, y se hace referencia a los ecosistemas en los que se recogen. Se ha observado que los hongos silvestres representan un valor reducido en comparación con otros recursos forestales no madereros (RFNM). Esto se debe en parte al desconocimiento taxonómico: todos los hongos reciben el mismo nombre local "Enguday". Este es un recurso muy poco estudiado si se compara con otros RFNMs, lo que hace que esté especialmente amenazado debido a los pocos estudios etnomicológicos llevados a cabo hasta el momento en el país. Por todo ello, pensamos que este estudio puede suponer un punto de partida fundamental para posteriores trabajos que contribuyan a un mayor conocimiento de este recurso en Etiopía, lo que conllevará una mayor promoción y conservación de los hongos silvestres comestibles y medicinales en el país.

Palabras clave: Hongos silvestres, Enguday, etnomicología, producto forestal no maderero, Etiopía

\section{INTRODUCTION}

Ethiopia encompasses a broad range of ecosystems, with great ranges of altitude, rainfall patterns and soil variability which contribute to the occurrence of different life forms both in flora and fauna (Bongers and Tenngkeit, 2010; Friis et al., 2010). The existence of high variation in macro- and micro-climatic conditions has also contributed to the formation of diverse vegetation types in the country. Friis et al. (2010) classified the vegetation resources of Ethiopia into 12 types that range from Afro-alpine formations through dense high canopy montane forests to savanna, scrubland and deserts. An important feature of these vegetation types is their richness in valuable types of Non-Timber Forest Products (NTFPs) (Adilo, 2007; Seyoum, 2007; Sultan, 2009). The most important NTFPs include honey, bees-wax, bamboo, gum arabic, resin, coffee, spices, incense, and edible plant products like fruits, seeds, fodder, medicinal plants, mushrooms, as well as various extractives and flavorings (Asfaw and Tadesse, 2001; Lulekal et al., 2011).

Wild mushrooms are parts of the livelihood of people in different parts of the world (Boa, 2004; Manoharachary et al., 2005; Sarma et al., 2010). They have long been collected as valuable NTFPs, generate cash income by market trade, and are used for local subsistence in food and traditional medicine (Boa, 2004; Chang and Lee, 2004; Mau et al., 2004). This practices help rural people reduce vulnerability to poverty and strengthen their livelihoods through a reliable income and have turned ethnomycology into a discipline in different parts of the world (Boa, 2004). In Ethiopia, however, wild edible mushrooms are the most neglected NTFPs resources. Despite their importance, wild mushrooms have been given little attention, and they are less studied and rarely documented (Alemu, 2013; Muleta et al., 2013). Then again, the justification behind forest resource 
management in the country has been primarily based on the production of wood products (Yemiru et al., 2010). The values and roles of NTFPs like mushrooms have been neglected and all activities related to forest management are focused on maximizing wood products (Asfaw and Tadesse, 2001; Lulekal et al., 2011; Melaku et al., 2014).

However, if managed and conserved properly, mushrooms could potentially support the livelihoods of rural people as major sources of food, medicine, and means of cash. Interestingly, other studies in different part of the world indicated that wild mushrooms could play key roles in local economic developments. In some cases, they could generate even higher economic benefits than timber productions (Oria-de-Rueda et al., 2008). Thus, this could help reconcile the social, economic and ecological values of the forests and could encourage the rural people to rationally manage and conserve forest resources in their locality.

Various ethnobotanical studies undertaken in Ethiopia have already revealed long lists of NTFPs, indicating their importance, contribution and use by rural communities (Lulekal et al., 2011; Melaku et al., 2014). However, reports on mushrooms rarely exist, and the available reports contain scanty and basic information about their existence and use at some community levels (Abate, 2014; Muleta et al., 2013; Tuno, 2001). Efforts are needed to integrate wild mushrooms into the mainstream of NTFPs in the country to ensure their conservation and enhance their value in human welfare.

One strategy could be documentation and dissemination of information related to important edible and medicinal mushrooms and their ethnomycological uses to promote their added values, aside from subsistence, around the country. Therefore, this paper attempts to review and compile the diversity of wild edible and medicinal mushrooms in Ethiopia. Comprehensive information on the traditional practices regarding the use by certain ethnic tribes in the country was also documented through reviewing available information. Thus, this paper could serve as a baseline document for further research in Ethiopia.

\section{MUSHROOM COLLECTION AND USE}

Wild mushrooms have been utilized as important sources of food and medicine by rural communities that mostly depend on forests for their livelihoods. Such ethnomycological usage has been also traditional among the forest dweller communities in Ethiopia. The term "Enguday" or "Yejib tila" is commonly used by people to call wild edible mushrooms in the country. The literal meaning of "Yejib tila" is "shadow of the hyena" ("yejib": hyena and tila: "shadow") and implies wild mushrooms appear where hyenas cast shadows: wild mushrooms growth is somewhat mysterious (Abate, 2014). Although wild mushrooms have been used as food and traditional medicine sources (Asfaw and Tadesse, 2001; Semwal et al., 2014), indigenous knowledge among different tribes has not been given significant attention. Additionally, the documented information on the collection, its use and list of valuable mushrooms, is limited. In this section, we summarize available ethnomycological notes to serve as a compressive reference and for further investigations.

\section{Mushroom use as food}

Available ethno-mycological literature provided a good illustration of certain ethnic groups use of wild mushrooms as a food source. For example, Tuno (2001) described the traditional use of wild mushrooms by the Majangir ethnic groups as a subsidiary food gathered from the natural forests in southern Ethiopia. Muleta et al. (2013) and Abate (2014) also documented the culture of hunting and traditional use of mushrooms by the Kaffa ethnic groups in the southwest part of the country. In both cases local wild mushrooms have a long history as part of their livelihood because of their nutritional value and good taste (Muleta et al., 2013; Tuno, 2001). Those mushrooms collected from the forest are eaten fresh and efforts to preserve are not a widespread practice in either of the two ethnic groups.

Other important ethnomycological resources also come from Muleta et al. (2013) who indicated the existence of mushroom hunting cultural practices in the Bonga area in the southern region. In his research, Muleta et al. (2013) mentioned wild edible mushrooms are important sources of food supplement for rural communities, and the rural people preferred mushrooms primarily because of their unique flavor and texture. Mushrooms are used to make soup, salad and other traditional meals. The rare practice of mushroom drying and preservation existed among the local communities in the Bonga area (Muleta et al., 2013).

A noticeable interest on wild mushrooms was also reported at the Benihsnagul Gumz region, western Ethiopia (Alemu et al., 2012). In this region, the main tribal groups i.e. Gumz and Berta are practicing mushroom collection for subsistence, and they appreciate mushrooms as valuable food sources. They also use mushrooms as seasonal coping food, during food shortage periods, mainly in the rainy season when grain scarcity occurs (Alemu et al., 2012).

Wild mushroom fruiting and collection are restricted to the rainy season, mainly from June to September in Ethiopia. For some species like Lentinus sp., collection occurs during the dry season (Tuno, 2001). The most commonly used species, shown in Table 1, include Agaricus arvensis, 
A. campestroides, Laetiporus sulphureus, Termitomyces microcarpus, T. clypeatus, Lentinus sp., Schizophyllum commune and Dictyophora indusiata (Abate, 2014, 2008; Muleta et al., 2013; Tuno, 2001). Among these species, L. sulphureus and S. commune are well exploited and documented for their ethnomycological use in Ethiopia (Tuno, 2001). Habitat information for commonly used species was also noted (Table 1): they grow mainly in natural forests, grazing areas and termite mounds (Abate, 2014). However, taxonomic description and voucher collections of most of the species are lacking, indicating further work is needed in fungi taxonomy and classification. The information from the literature is very limited and does not reflect the wider cultural usage in the country. Thus, as there are numerous benefits that can be derived from traditional uses, further ethnomycological work is clearly needed to maximize the benefits from traditional knowledge and use of wild mushroom resources in Ethiopia.

\section{Mushrooms as traditional medicine}

Wild mushrooms are known to be rich sources of various bioactive substances (Lindequist et al., 2005) and many of them have been reported to be used in folk medicine worldwide (Hobbs, 1995). Interestingly, traditional medicinal uses of mushrooms are reported by Abate (2014) from the Kaffa ethnic groups in southern Ethiopia. Among other species, Laetiporus sulphureus is reported to be commonly used for treating pain during childbirth, and its powder is usually preserved for long periods of time to use as drug during child delivery in Kaffa area (Abate, 2014).

The medicinal use of mushrooms, whose traditional knowledge for the practice is handed down generational lines via oral communications, has also been reported by Alemu et al. (2012) from the Benihsnagul Gumz region, western Ethiopia. In all cases, most of the knowledge on medicinal uses was found to be confined to elderly people of the village or handled secretly by traditional healers of the locality. They both are key informants for the identification of medicinal species since they use different mushrooms for their traditional medicinal practices (Abate, 2008). Consequently it is difficult to get list of species that have been used traditionally for medicinal purpose from any ordinary person (Abate, 2014). Thus, further documentation and ethnomedicinal uses study will be important for enhancing the understanding of indigenous knowledge systems and the list of species used in folk medicine in Ethiopia. List of species used for traditional medicinal purpose is provided (Table 1).

\section{Mushrooms for market sale}

Wild mushrooms are generally not among NTFPs for sale in Ethiopia. They are collected mostly for subsistence use (Yehuala, 2010). The major reason is that the season for wild mushroom growth is short and during this season everyone can collect from the wild for their own consumption. However, in some places wild edible mushrooms can provide additional income to households when sold in the markets. For example, in local markets of Bonga and Assosa, mushrooms are available occasionally in association with other vegetal products (Abate, 2014), which the local people sell to earn some income to supplement their household economy. The common species found fresh in local markets includes Agaricus sp., Laetiporus sp., and Termitomyces sp. (Abate, 2014). However, their market value is very low as the buyers are restricted among the local tribes, and many people were found to be quite ignorant about their edibility (Abate, 2014). Moreover, awareness to use mushrooms as a potential source of income in most rural part of the country is very low, and complete lists of species for the local markets is also lacking in all the literature. Traditional taboos such as considering collecting wild edible mushrooms as a sign of poverty also hinders wider mushroom utilization in a major part of the country, indicating that increasing awareness through collaborative efforts are essential to assist the nationwide efforts to combat food insecurity and ensure nutritional diversity in Ethiopia. List of species used for sale in some localities is presented in Table 1.

\section{Gender and mushrooms}

In Ethiopia, women are usually involved in collection of mushrooms and they recognize more fungi species than men. Children are also involved in the collection of some specific taxa like Termitomyces sp. (Abate, 2014; Alemu, 2013). Women have also basic knowledge of mushrooms in terms of habitats, niche, and associated substrates. They have also expertise to distinguish between edible and poisonous species. This might be because they are more often involved in preparing and cooking mushrooms than men. Although it differs from place to place, the most recognized ways used to classify mushrooms as edible and non-edible are the colors, shapes and the presence or absence of strong bad smell (Tuno, 2001). These all help for the successful collection of wild edible mushrooms in the locality. The traditional processing knowledge, including handling and cooking are also well known and handled by women (Abate, 2014; Muleta et al., 2013).

\section{Checklist of wild edible mushrooms}

The majority of the rural population in Ethiopia is dependent on forest resources, either in the form of subsistence or as a cash income derived from NTFPs (Lulekal et al., 2011). Although mushrooms are NTFPs, 
Table 1. Summary of wild edible and medicinal mushrooms and their associated habitats in Ethiopia.

\begin{tabular}{|c|c|c|c|}
\hline List of taxa & Use & Origin & Referred sources \\
\hline Agaricus arvensis Schaeff. & $F, S$ & GA & $\begin{array}{l}\text { Abate (2008); Alemu (2013); Muleta et al. } \\
\text { (2013); Sitotaw et al. (2015a) }\end{array}$ \\
\hline Agaricus campestroides Heinem \& Gooss.-Font. & $F, S$ & $N F, G A$ & $\begin{array}{l}\text { Abate (2014); Alemu (2013); Dejene et al. } \\
\text { (2017), Sitotaw et al. (2015a); Woldegiorgis } \\
\text { et al. (2014) }\end{array}$ \\
\hline Agaricus subedulis Heinem. & $\mathrm{F}$ & NF & Dejene et al. (2017), (2016) \\
\hline Agrocybe pediades (Fr.) Fayod & $\mathrm{F}$ & NF & Dejene et al., 2016 \\
\hline Armillaria heimii Pegler. & FM & NF & $\begin{array}{l}\text { Abate (2014), (2008); Dejene et al. (2016); } \\
\text { Osarenkhoe et al. (2014) }\end{array}$ \\
\hline Auricularia sp. Bull. ex Juss. & FM & NF & $\begin{array}{l}\text { Abate (2008); Osarenkhoe et al. (2014); } \\
\text { Woldegiorgis et al. (2014) }\end{array}$ \\
\hline Calvatia rubroflava (Cragin) Lloyd & FM & NF & Dejene et al. (2016) \\
\hline Coprinellus domesticus (Bolton) Vilgalys, Hopple \& Jacq. & $\mathrm{F}$ & NF & Dejene et al. (2017), (2016) \\
\hline $\begin{array}{l}\text { Johnson. } \\
\text { Coprinopsis nivea (Pers.) Redhead, Vilgalys \& Moncalvo }\end{array}$ & $\mathrm{F}$ & NF & Dejene et al. (2016) \\
\hline Coprinus pseudoplicatilis Voglino & $\mathrm{F}$ & NF & Abate (2014), (2008) \\
\hline Hygrophoropsis aurantiaca (Wulfen) Maire. & $\mathrm{F}$ & NF & Dejene et al. (2017), (2016) \\
\hline Hymenagaricus sp. Heinem. & $\mathrm{F}$ & NF & Dejene et al. (2017), (2016) \\
\hline Laetiporus sulphureus (Bull.) Murrill & $\mathrm{FM}, \mathrm{S}$ & NF & $\begin{array}{l}\text { Alemu (2013); Dejene et al. (2016); Muleta } \\
\text { et al.(2013); Osarenkhoe et al. (2014); } \\
\text { Tuno (2001); Woldegiorgis et al. (2014) }\end{array}$ \\
\hline Lentinus sp. Fr. & FM, S & NF & (Osarenkhoe et al., 2014; Tuno, 2001) \\
\hline Leucoagaricus holosericeus (J.J. Planer) M.M. Moser. & F & NF & Dejene et al. (2017), (2016) \\
\hline Leucoagaricus leucothites (Vittad.) Wasser. & $\mathrm{F}$ & NF & Dejene et al. (2017), (2016) \\
\hline Leucoagaricus rubrotinctus (Peck) Singer. & $\mathrm{F}$ & NF & Dejene et al. (2017), (2016) \\
\hline Leucocoprinus birnbaumii (Corda) Singer. & $\mathrm{F}$ & NF & Dejene et al. (2016) \\
\hline Leucocoprinus cepistipes (Sowerby) Pat. & $\mathrm{F}$ & NF & Dejene et al. (2017), (2016) \\
\hline Lycoperdon sp. Pers. & F & NF & Dejene et al. (2016) \\
\hline Macrolepiota sp. Singer & $\mathrm{F}$ & $N F, G A$ & $\begin{array}{l}\text { Abate (2008); Alemu (2013); Woldegiorgis } \\
\text { et al. (2014) }\end{array}$ \\
\hline Pholiota sp. (Fr.) P. Kumm. & $\mathrm{F}$ & NF & Abate (2014), (2008) \\
\hline Schizophyllum commune Fr. & FM & NF & $\begin{array}{l}\text { Alemu (2013); Osarenkhoe et al. (2014); } \\
\text { Tuno (2001) }\end{array}$ \\
\hline Suillus luteus (L.) Roussel & $\mathrm{F}$ & PT & $\begin{array}{l}\text { Abate (2008); Semwal et al. (2014); } \\
\text { Woldegiorgis et al. (2014) }\end{array}$ \\
\hline Termitomyces aurantiacus (R. Heim) R. Heim & $\mathrm{F}$ & TM & Sitotaw et al. (2015b) \\
\hline Termitomyces clypeatus R. Heim & $F, S$ & TM & $\begin{array}{l}\text { Alemu (2013); Muleta et al. (2013); Sitotaw } \\
\text { et al. (2015b) }\end{array}$ \\
\hline Termitomyces eurrhizus (Berk.) R. Heim & $\mathrm{F}$ & $\mathrm{TM}$ & Sitotaw et al. (2015b) \\
\hline Termitomyces le-testui (Pat.) R. Heim & F & TM & Sitotaw et al. (2015b) \\
\hline Termitomyces microcarpus (Berk. \& Broome) R. Heim & FM, S & TM & $\begin{array}{l}\text { Abate (2014); Alemu (2013); Muleta et al. } \\
\text { (2013); Osarenkhoe et al. (2014) }\end{array}$ \\
\hline Termitomyces robustus (Beeli) R. Heim & FM & TM & $\begin{array}{l}\text { Osarenkhoe et al. (2014); Sitotaw et al. } \\
\text { (2015b) }\end{array}$ \\
\hline Termitomyces schimperi (Pat.) R. Heim & $\mathrm{F}$ & TM & Sitotaw et al. (2015b) \\
\hline Tylopilus niger (Heinem. \& Gooss.-Font.) Wolfe & $\mathrm{F}$ & PT & Dejene et al. (2017) \\
\hline Vascellum sp. F. Smarda & $\mathrm{F}$ & GA & Abate (2014); Alemu (2013) \\
\hline
\end{tabular}

Note: GA: grazing area, NF: natural forest, TM: termite mounds and PT: plantation forest, F: food and FM: Food and Medicine, and S: For sale. 
information on their diversity is hardly ever documented and the country remains mycologically unexplored (Sitotaw et al., 2015b). So far, limited number of species with saprobic or ectomycorrhizal habits have been reported from different regions.

The most important published reports on list of mushrooms in Ethiopia comes from the work of Abate (2014), (2008); Alemu (2013) and Muleta et al. (2013) from natural forests in the highlands of the country. Some specific Agaricus species were reported by Abate (1999) and Sitotaw et al. (2015a) from the Afro-montane forest regions in central Ethiopia. Moreover, Tuno (2001) also reported few edible mushrooms from the moist Afro-montane forest systems in the southwest part of the country. Most recently, Sitotaw et al. (2015b) described seven edible Termitomyces species in the western lowland part, where the Combretum - Terminalia woodland vegetations are dominant. A compilation of the wild edible or medicinal mushrooms and their associated habitats reported from Ethiopia are presented (Table 1). Up-to-date fungal taxa names and authors' names were obtained from Mycobank database (http://www. mycobank.org).

Some other researchers also have reported the potential availability of wild edible mushrooms in plantation forest systems from Ethiopia (Megersa et al., 2017; Semwal et al., 2014). They highlight the existence of valuable genera such as Suillus, Lactarius, Lepista and Cantharellus. In a similar way, a survey report of NTFPs from the Combretum-Terminalia woodland vegetations in Western Ethiopia reflected wider availability of edible mushrooms (Alemu et al., 2012). However, this report lacks field observations that justify the claims, and the species mentioned here are not properly identified. Almost all the species lack scientific names, underlining the fact that the majority of wild mushrooms in Ethiopia remain unnamed or await scientific description.

More recently, our research team reported a total of 26 wild edible mushrooms from natural and exotic forest plantations in southern Ethiopia (Dejene et al., 2017, 2016). Most species are not known by the local communities, and their edibility was assessed from other countries experiences. Interestingly, we found some edible mycorrhizal mushroom in non-native tree plantation forests. A list of the species reported are presented (Table 1), and photographs of some of the wild edible mushrooms collected are illustrated (Figure 1).

\section{CONCLUSIONS}

By and large, the reviewed literature showed wild mushroom gathering as accessible food source, and in tradi- tional medicine their use is a common practice in Ethiopia; wild mushrooms also have economic importance to local people in some localities. However, all the available ethnomycological notes focused on specific areas such as the west and southwest parts of the country, and most of the country still remains unexplored. This indicates that the information contained is inadequate and does not convey the full ethnomycological picture of the country, as Ethiopia is characterized by many communities that might have long histories of wild mushroom usage with wider traditional knowledge in the culture. Thus, we encourage more research and documentation to reveal the humanmushroom relationships in depth in the country.

On the other hand, the reviewed literature did highlight the potential existence of wild edible and medicinal mushrooms in Ethiopia. More interestingly, some lists of common species used in the country have been indicated even though many species and their diverse uses remain unidentified, undescribed, and undocumented. This indicates that wild mushrooms have suffered many years of neglect and some of the species might face extinction as their habitats are being altered in the country. Consequently, mushroom resources in Ethiopia remained under-represented in the literature. Thus, further studies are needed for effective and potential utilization of wild mushrooms, as well as wild mushroom conservation in the country.

\section{ACKNOWLEDGEMENTS}

We thank Dr. Luis Santos del Blanco (IDForest) for his helpful comments for improving this paper. This work is supported by Erasmus Mundus-Dream project grant.

\section{BIBLIOGRAPHY}

Abate D. (2014) Wild mushrooms and mushroom cultivation efforts in Ethiopia. World Society for Mushroom Biology and Mushroom Products (WSMBMP) Bulletin 11. http://wsmbmp.org/ bol1 1/B-11\%20Enguday.pdf

Abate D. (2008) Wild mushrooms in Ethiopia and our eating habit. In: National Mushroom Conference, Faculty of Science, Addis Ababa University, May 14-15. Addis Ababa, Ethiopia. 42 p.

Abate D. (1999) Agaricus campestris in upland Ethiopia. Mycologist $13: 28$

Adilo M. (2007) The contribution of non-timber forest products to rural livelihood in Southwest Ethiopia. MSc Thesis. Wageningen University, the Netherlands.

Alemu F. (2013) Assessment of wild mushrooms and wood decaying fungi in Dilla University, main campus, Ethiopia. International Journal of Advanced Research 1:458-467.

Alemu H., N. Debela, A. Mamuye and M. Jano (2012) Wild Edible Plants by Gumuz Tribes as nutritious and sustainable food stuffs in the Metekel and Kamashi Zones of Benishangul-Gumuz Regional State. An assessments report submitted to Tikuret Legumuz Hizb Limat Mahibr, Assosa Ethiopia.

Asfaw Z. and M. Tadesse (2001) Prospects for sustainable use and development of wild food plants in Ethiopia. Economic Botany 55:47-62.

Boa E. (2004) Wild Edible Fungi: A Global Overview of their Use and 


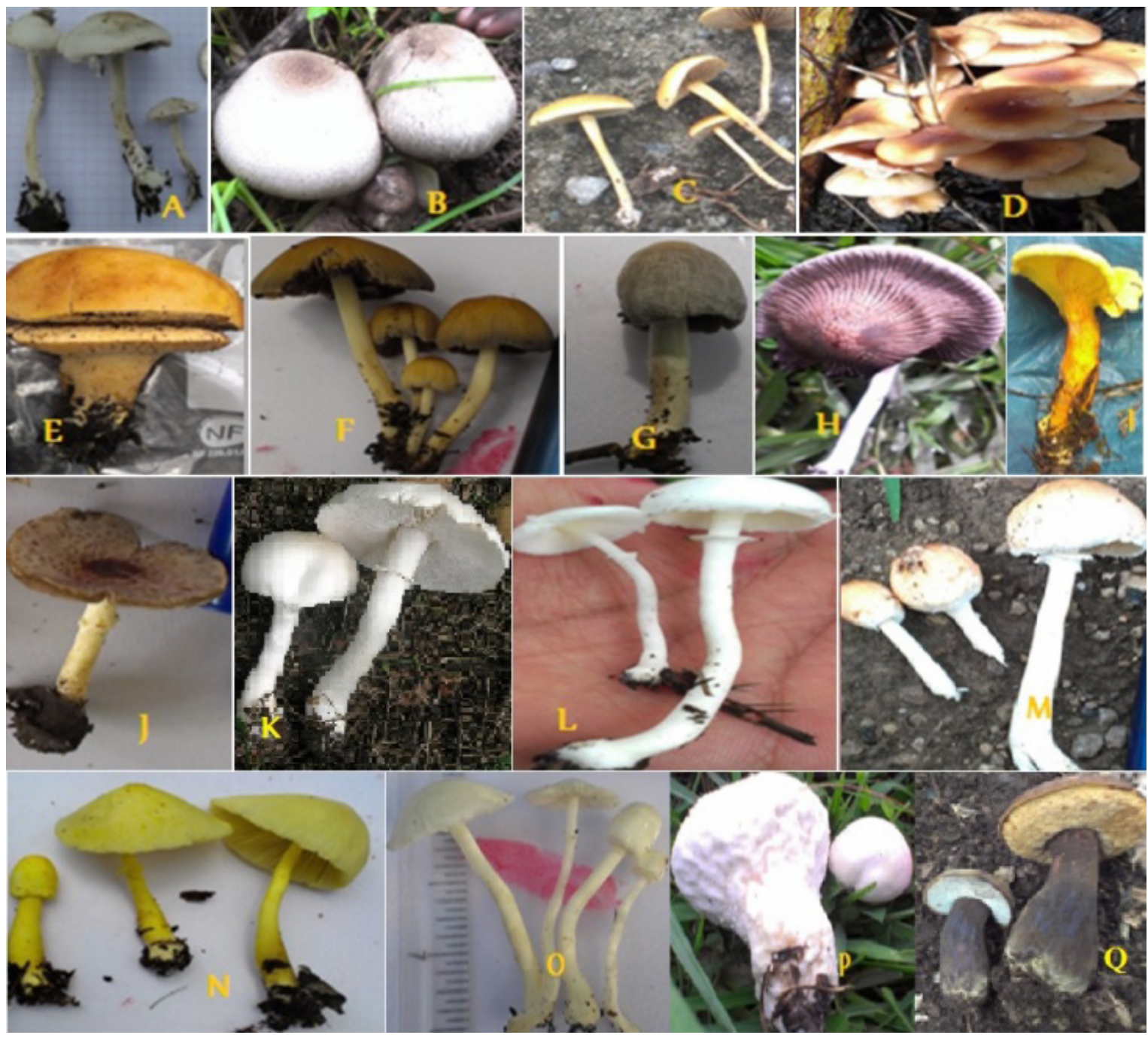

Figure 1. Pictures of some wild edible mushrooms in Ethiopian forests: (A) Agaricus campestroides, (B) Agaricus subedulis, (C) Agrocybe pediades, (D) Armillaria heimii, (E) Calvatia rubroflava, (F) Coprinellus domesticus, (G) Coprinopsis nivea, $(\mathrm{H})$ Coprinus pseudoplicatilis, (I) Hygrophoropsis aurantiaca, $(\mathrm{J})$ Hymenagaricus fuscobrunneus, (K) Leucoagaricus holosericeus, (L) Leucoagaricus leucothites, (M) Leucoagaricus rubrotinctus, (N) Leucocoprinus birnbaumii, (O) Leucocoprinus cepistipes, (P) Lycoperdon perlatum and (Q) Tylopilus niger (Photos by Tatek, 2015).

Importance to People. FAO Technical Paper. Non-wood Forest Products 17. Food and Agriculture Organization. Rome, Italy. $157 \mathrm{p}$.

Bongers F. and T. Tennigkeit (2010) Degraded forests in Eastern Africa: Introduction. In: Degraded Forests in Eastern Africa: Management and Restoration. F. Bongers and T. Tennigkeit, T. (eds.). Earthscan Ltd., London, UK. pp:1-18.

Chang Y. S. and Lee S. S. (2004) Utilisation of macrofungi species in Malaysia. Fungal Diversity 15:15-22.

Dejene T., J. Oria-de-Rueda and P. Martín-Pinto (2016) Macrofungal species diversity and sporocarp production following wildfire in dry Afromontane forests of Ethiopia. Abstract. Xth Young Researchers Meeting on Conservation and Sustainable Use of Forest Systems, Palencia \& Valsaín (Spain), 25-26th January. Sustainable Forest Management Research Institute (University of Valladolid-INIA). $53 \mathrm{p}$.

Dejene T., Oria-de-Rueda J. A. and P. Martín-Pinto (2017) Fungal diversity and succession following stand development in Pinus patula Schiede ex Schltdl. \& Cham. plantations in Ethiopia. Forest Ecology and Management 395:9-18.

Friis I, S. Demissew and P. van Breugel (2010) Atlas of the Potential Vege- tation of Ethiopia. The Royal Danish Academy of Sciences and Letters. Copenhagen, Denmark. 306 p.

Hobbs C. (1995) Medicinal Mushrooms: An Exploration of Tradition, Healing, and Culture. 2nd ed. Botanica Press. Santa Cruz, CA USA. $251 \mathrm{p}$

Lindequist U., T. H. J. Niedermeyer and W. D. Jülich (2005) The pharmacological potential of mushrooms. Evidence-Based Complementary and Alternative Medicine 2:285-299.

Lulekal E., Z. Asfaw, E. Kelbessa and P. Van Damme (2011) Wild edible plants in Ethiopia : a review on their potential to combat food insecurity. Afrika Focus 24:71-121.

Manoharachary C., K. Sridhar, R. Singh, A. Adholeya, T. S. Suryanarayanan, S. Rawat and B. N. Johri (2005) Fungal biodiversity: distribution, conservation and prospecting of fungi from India. Current Science 89:58-71

Mau J. L., C. N. Chang, S. J. Huang and C. C. Chen C. (2004) Antioxidant properties of methanolic extracts from Grifola frondosa, Morchella esculenta and Termitomyces albuminosus mycelia. Food Chemistry 87:111-118.

Megersa S., A. Gure, S. Feleke and M. Alemu M. (2017) Macrofungi species richness and diversity in Dagaga and Gambo plantation and 
natural forests of Arsi Forest Enterprise, Oromia, Ethiopia. Imperial Jorunal of Interdisciplinary Research 3:1681-1686.

Melaku E., Z. Ewnetu and D. Teketay (2014) Non-timber forest products and household incomes in Bonga forest area, southwestern Ethiopia. Journal of Forestry Research 25:215-223.

Muleta D., D. Woyessa and T. Yenealem (2013) Mushroom consumption habits of Wacha Kebele residents, southwestern Ethiopia. Global Research Journal of Agricultural and Biological Sciences 4:6-16.

Oria-de-Rueda J. A., P. Martín-Pinto and J. Olaizola (2008) Bolete productivity of Cistaceous scrublands in Northwestern Spain. Economic Botany 62:323-330.

Osarenkhoe 0. 0., O. A. John and D. A. Theophilus (2014) Ethnomycological conspectus of West African mushrooms: an awareness document. Advances in Microbiology 4:39-54.

Sarma T. C., I. Sarma and B. N. Patiri (2010) Wild edible mushrooms used by some ethnic tribes of Western Assam. The Bioscan 3:613625

Semwal K. C., H. Lemma, A. Dhyani, G. Equar and S. Amhare (2014) Mushroom: Nature's Treasure in Ethiopia. Momona Ethiopian Journal of Science 6:138-147.

Seyoum A. (2007) Economic value of Afromontane Natural Forests of Sheka Zone, Southwestern Ethiopia. In: Forest of Sheka. M. Fetene (ed.). Addis Ababa, Ethiopia. pp:183-218.
Sitotaw R., Y. Li, T. Z. Wei, D. Abate and Y. J. Yao (2015a) Two new records of Agaricus spp. from Ethiopia. Mycotaxon 130:1171-1183.

Sitotaw R., A. Mulat and D. Abate (2015b) Morphological and molecular studies on Termitomyces species of Menge District, Asossa Zone, Northwest Ethiopia. Science, Technology and Arts Research Journal 4:49-57.

Sultan M. (2009) The role of non-timber forest products to rural livelihoods and forest conservation: a case study at Harana Bulluk District Oromia National Regional State, Ethiopia. MSc Thesis Hawassa University.

Tuno N. (2001) Mushroom utilization by the Majangir, an Ethiopian tribe. Mycologist 15:78-79.

Woldegiorgis A. Z., D. Abate, G. D. Haki and G. R. Ziegler (2014) Antioxidant property of edible mushrooms collected from Ethiopia. Food Chemistry 157:30-36.

Yehuala K. (2010) Contribution of Small Scale Mushroom Production for Food Security in the Amhara Region, Ethiopia. In: Experience Sharing and Revitalization Workshop of Amhara Region Food Security Network. 26-27 August. Bahir Dar, Ethiopia. 28 p.

Yemiru T., A. Roos, B. M. Campbell and F. Bohlin (2010) Forest incomes and poverty alleviation under participatory forest management in the Bale Highlands, Southern Ethiopia. International Forestry Review 12:66-77. 
